\title{
Digital youth inclusion and the big data divide: examining the Scottish perspective
}

\author{
Alicja Pawluczuk \\ Institute in Macau, United Nations University, Macau SAR, China
}

Published on 28 May 2020 | DOI: 10.14763/2020.2.1480

\begin{abstract}
The aim of this article is to examine some of the emerging challenges associated with digital youth inclusion and the asymmetric power dynamics between those who collect data and those who are the targets of the data collection process - commonly referred to as the "big data divide'. Digital inclusion is understood here as a strategy to ensure that all people have equal opportunities and appropriate skills to access and benefit from digital technologies. Digital inclusion practice encompasses a range of methods and approaches used to help individuals and communities to access and understand digital technologies. While the literature analysis is framed within a wider, international context, the discussion is primarily situated within Scotland's studies. The analysis presented here reveals that many existing youth digital inclusion programmes are corporate-led and primarily focus on functional digital literacy (e.g., how to access information online), and not critical digital literacy (e.g., how to critically analyse the information online). I argue here that digital inclusion should not solely be viewed as a strategy for employment and education, but as a set of larger, systematic, continually evolving, and critical youth engagement practice. In the era of the 'big data divide', digital inclusion programmes should aim to enable young people's critical digital abilities to continually review and respond to their positions within the power structures of the data society. To achieve this, I propose three areas for consideration for youth digital inclusion practice.
\end{abstract}

Keywords: Digital divide, Digital inclusion, Youth

\section{Article information}

Received: 04 Sep 2020 Reviewed: 24 Jan 2020 Published: 28 May 2020

Licence: Creative Commons Attribution 3.0 Germany

Competing interests: The author has declared that no competing interests exist that have influenced the text.

URL:

http://policyreview.info/articles/analysis/digital-youth-inclusion-and-big-data-divide-examining-scotti sh-perspective

Citation: Pawluczuk, A. (2020). Digital youth inclusion and the big data divide: examining the Scottish perspective. Internet Policy Review, 9(2). https://doi.org/10.14763/2020.2.1480

This paper is part of Digital inclusion and data literacy, a special issue of Internet Policy Review guest-edited by Elinor Carmi and Simeon J. Yates. 


\section{INTRODUCTION}

Globally, young people aged 15-24 account for nearly one-fourth of internet users (ITU, 2019). In the light of the increasing digitalisation of society, understanding young people's digital inclusion has become an important topic for researchers (Helsper, 2017; Gangneux, 2019) and policymakers (European Commission, 2018). Digital inclusion is defined as a strategy to ensure that all people have equal opportunities and appropriate skills to access and benefit from digital technologies (ITU, 2019). Digital inclusion practice encompasses a range of methods and approaches used to help individuals and communities to access and understand digital technologies.

In recent years, there has been a growing interest in the use of digital technologies in the out-ofschool learning settings (Harvey, 2016; Ito et al., 2015). Such non-formal education programmes have a potential to recognise and address young people digital skills and needs, which might be omitted at schools or at home (Black et al., 2015). Examples of prior European youth digital inclusion programmes include coding clubs, discussion groups (e.g., focusing on issues related to online safety), and hackathons (for more examples see www.digitalyouthwork.eu).

Since 2015, the provision of out-of-school digital youth inclusion projects has also become prominent in Scotland (Youth Link Scotland, 2020). As many young Scots still have limited digital literacy (e.g., regarding privacy issues and safe online communications) or internet access, youth digital inclusion has become a priority for policymakers (Scottish Government, 2017), researchers (Gangneux, 2019; Helsper, 2017; Livingstone \& Helsper, 2007), and young Scottish activists (5 Rights Youth Commission, 2017). There is an overall agreement that it is essential to ensure that all young people have access to online services and digital literacy support. In fact, the importance of digital youth inclusion and digital literacy education was highlighted in the National Digital Strategy for Scotland document, published in 2017. The strategy document states that the Scottish government's aim is to equip “children and young people with the increasingly sophisticated and creative digital skills they need to thrive in modern society and the workplace" (Digital Scotland, 2017a, p. 24). The importance of inclusive and youth-centred education was also outlined by young Scottish researchers, who argued that both students and educators require ongoing digital skills support (5 Rights Youth Commision, 2017).

However, while the information on why youth digital inclusion is important, the analysis on how to effectively contextualise, organise, and manage a youth digital inclusion project is still limited. In Scotland, there is a scarcity of information on how to address youth digital inclusion in times of the big data divide. The big data divide is understood here as an asymmetric power dynamic between those who collect, analyse and benefit from data (e.g., social media companies), and those who are the targets of the data collection process (e.g social media users) (Andrejevic, 2016).

In this paper, I examine the existing Scottish youth digital strategies and contextualise them within a wider scholarly discourse on digital literacy and the big data divide. Throughout this paper the term digital literacy is used to refer to young people's practical use of digital technologies in everyday life as well as the process of 'translating' these digital activities into beneficial real-world outcomes (Helsper, 2015). I also examine the importance of young people's critical thinking and critical digital participation. To this end, I ground my analysis in Polizzi's 
definition of critical digital literacy, who sees it as "an ensemble of critical abilities, knowledge and interpretations that are essential in the context of democratic participation and social inclusion in the digital age" (2019, p. 2). Thus, in the context of this paper, the 'critical' refers to young people's critical thinking in their everyday interactions with the digital technologies both in terms of the practical use and the pro-active analysis of their role and impact on society. I propose that digital inclusion should not only be viewed as a strategy for employment and education, but as a larger, systematic, continually evolving, and critical youth engagement practice.

The aim of this article is to examine some of the emerging challenges associated with digital youth inclusion and the big data divide, and to propose some critical considerations for digital youth inclusion practitioners. The analysis presented here draws from the scholarly discussion on digital youth participation (Eynon \& Geniets, 2016; Helsper, 2017; Livingstone \& Third, 2017), digital inclusion (Gangadharan, 2017; Livingstone \& Helsper, 2007; Scottish Government, 2017), and big data divide (Andrejevic, 2014). The contribution of this paper is its evaluations and recommendations based on three critical areas of focus in the process of establishing digital youth inclusion provisions: (1) digital youth inclusion provision: control and definition of the process; (2) a holistic examination of young people's digital needs, aspirations, and fears; and (3) a consideration of the impact on young people's human rights in the era of the big data divide. The analysis presented here is grounded both in my prior academic research on youth digital inclusion (see Pawluczuk et al., 2019) and direct experience of working 'in the field' as a youth digital inclusion worker in Scotland.

\section{DIGITAL YOUTH INCLUSION IN THE ERA OF THE BIG DATA DIVIDE}

The use of digital technologies among young people in the West has rapidly increased in the 21st century (Anderson \& Jiang, 2018; Ofcom, 2016). The continually evolving relationship between young people and digital technologies has become a central research theme for scholars (Akom, Shah, Nakai, \& Cruz, 2016; Fitton, Little, \& Bell, 2016; Ito et al., 2015), policymakers (European Commission, 2018), as well as youth participation and education practitioners (Harvey, 2016; Wilson \& Grant, 2017). Livingstone and Third propose that youth digital inclusion is "a staged process in which the benefits of internet use depend not only on age, gender, and SES [socioeconomic status], but also on the amount of use and online expertise" (2007, p. 691). In this article, the United Nations' definition of youth is adopted, which describes young people as those aged 15-24 (UN Department of Economic and Social \& Youth, 2017). Some scholarly accounts (Little et al., 2016) view young people as "[the] most diverse, dynamic, exciting, and technologically aware user groups that will soon become the next generation of adults" (2016, p. 1). In $2016,91 \%$ of young people in the European Union (EU) made daily use of the internet, compared with $71 \%$ of the whole EU population. In the EU, $83 \%$ of young people use mobile phones for internet access away from home or work (eurostat, 2017). A recent UK report revealed that $99 \%$ of young people in the United Kingdom between the ages of 14 and 34 were described as "recent Internet users" 1 (Office for National Statistics, 2018, p. 8). Increasing digital youth access and participation can also be noted in Scotland, where in 2018 "superfast Internet" 2 coverage has increased to $92 \%$ of homes and businesses, an increase from $87 \%$ in 2017 (Ofcom, 2018). In 2016, the Scottish Household Survey reported that only $1 \%$ of young Scots aged 16 to 24 do not use the internet (Scottish Government, 2016). Therefore, while it is evident that young people are accessing the Internet, the quality of their digital participation 
needs further examination.

The importance of youth digital expertise and their proactive role in the digital age is reflected in the way scholars define young people - digital participants, makers, and 'doers' (Ito et al., 2013, p. 6) and digital solutions co-designers (Fitton \& Bell, 2014). Indeed, youth-led online movements such as the Global Climate Strike (UK Student Climate Network, 2019) or the campaign for the provision of free menstrual products (Free Periods, 2019) are examples of how those aged under 18 can and do use technologies to drive positive social change. Thus, it can be argued that the digital age has enabled some young people to exercise their voices and participate in civic activities as engaged citizens (Ito et al., 2015)

However, the emancipating qualities of the digital world ought not to be romanticised (Buckingham, 2008). While the digitalisation of societies has led to empowerment for some young people, it has also accelerated some of the pre-internet forms of youth social exclusion as well as created new ones (Vartanova \& Gladkova, 2019). The building blocks of the modernday digital infrastructure, such as "algorithmic selection, surveillance, and big data, have created new forms of inequality that follow the traditional cultural patterns of class, gender, wealth, and education" (Trappel, 2019, p. 9). Many disadvantaged young people in the United Kingdom still lack access to a computer or to the internet, which may result in lack of functional digital literacy and thus employability skills (e.g., using Word processor, completing online work applications) (Weston, Lumley, \& Curvers, 2018). As stated by Weston et al., “[t]o a young person who's struggling financially, is lacking stable housing and a meaningful career, is trying to plot a path towards their goals, accessing technology may seem low-priority" (2018, p. 4). Digital exclusion and limited digital and information literacy skills have been reported to lead to "confusion, frustration and defeatism online as well as offline" among young people (Van Deursen \& Helsper, 2018, p. 257). This sense of powerlessness and frustration as a result of inability to meaningfully participate online was also noted in Wilson and Grant's 2017 report on national youth digital inclusion. According to their research, one quarter of unemployed young people "dread" filling in online job applications, with one in ten avoiding the use of computers altogether. In this sense, the notion of online agency is not aligned with all 'youth' and clearly shows that previous inequality barriers to technologies persist on digital technologies.

Perhaps one of the more common tropes in the youth digital literacy debate is that they are, as Prensky argues - digital natives (Prensky, 2009). The term 'digital natives' assumes that young people born in the digital era will naturally adopt digital literacy and thus can be assumed to be digitally included in society. However, these narratives have been rebuked by various scholars (Helsper, 2015; Weston et al., 2018; Wilson \& Grant, 2017) who have questioned the validity of the so-called 'digital natives' in the United Kingdom. For example, researchers (Weston et al., 2018; Wilson \& Grant, 2017) found that many young people still require support to develop their digital literacy. Furthermore, Porat et al.'s (2018) research investigated young people's views on their digital literacy and found that young people tend to overestimate the levels of their digital literacy. The authors reported on young people's digital literacy overconfidence, which is reflected in some young people's limited social literacy online. For example, young people's abilities to share information, express personal opinion, and contextualise within others' information and opinions while participating in discussion groups (Porat, Blau, \& Barak, 2018) did not match the (considerably higher) perceptions of these skills. Thus, while young people might be often considered as already digitally connected and included, the debate on their digital participation reveals complexities.

Youth digital inclusion should also be examined in the context of the big data divide (e.g., 
Andrejevic, 2014; McCarthy, 2016). Andrejevic defines the big data divide as the process whereby people are separated from their data and excluded from the process of putting it to use" (2014, pp. 1685-1686). The big data divide reflects "both the relations of ownership and control that shape access to communication and information resources, and growing awareness of just how little people know about the ways in which their data might be turned back upon them" (Andrejevic, 2014, p. 1675). This problem of the big data divide is particularly important in the context of digital inclusion. As digitally excluded individuals are encouraged and pressured to participate in the digital world, they are also required to agree and comply with the terms and conditions which govern the power structures of the digital society. Thus, one's digital participation might often mean unconditional, uncontrollable, and overpowering data profiling. As argued by Barassi:

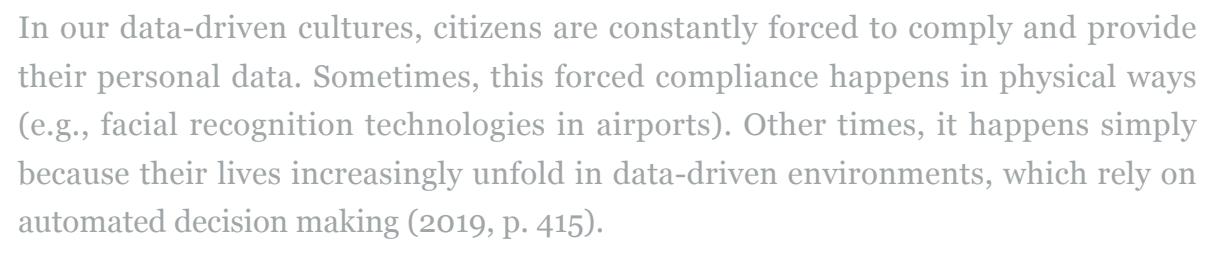

In this context of the big data divide, youths' information sharing and privacy practices require attention. Young people share more personal data than ever; $92 \%$ of teen social media users post their real names and 91\% post a photo of themselves (Chi et al., 2018). Chi et al. indicate that young people's growing digital footprints could be "used to track, profile, and shape young people throughout their lives" (Chi et al. 2018, p. 443). Literature analysis reveals that many young digital users are not aware of the ongoing data collection and retention and its possible privacy implications (Hautea el al., 2017). Young people's lack of access and understanding of how their data is analysed and shared might have direct consequences on a citizen's identity and a data subject's individual and collective self $\square$ determination (McCarthy, 2016). Among those young people who acknowledge the privacy implications of their digital participation, many also feel that they have no choice but to trade their personal information in the name of digital - and thus social - inclusion. While trying to simultaneously manage the opportunities and risks associated with their digital participation, young people report feeling fatigued, powerless, and sometimes even 'locked in' in their digital presence (Gangneux, 2019; Hargittai \& Marwick, 2016). As Hargittai and Marwick (2016) argue:
the assumption behind the existing opaque system is that businesses thrive on users sharing as much content as possible, and so do not benefit from clearer, more user- friendly options. The result of the current arrangement, however, is frustration that yields both apathy as well as self-censorship [among young people] (2016, p. 375).

It might be argued that while navigating within the multiple infrastructures of the digital world young people find themselves stuck between embracing (and being encouraged to embrace) the digital participation (e.g., employment opportunities) and protecting themselves from its possible side-effects (e.g., data mining, privacy breaches). Gangadharan (2017) reported that digital inclusion project participants are not prepared to confront the challenges posed by the big data divide. Many digital inclusion practitioners often lack the time and resources needed to cover privacy and online safety in their teaching programmes (Gangadharan, 2017), and do not provide project participants with opportunities to examine the critical element in their digital 
literacies. Thus, young people who are socially disadvantaged (e.g., lower socio-economic class) or from underrepresented communities (e.g., young people with disabilities or from ethnic minorities) who are not yet digitally included are at greater risk of becoming targets of the unethical practices associated with the digital and big data economies.

\section{YOUTH DIGITAL INCLUSION IN SCOTLAND: RESEARCH AND POLICY CONTEXT}

In recent years, the provision of out-of-school digital youth inclusion projects has become prominent in Scotland (Youth Link Scotland, 2020). The importance of informal digital education for young Scots was highlighted in the National Digital Strategy for Scotland, published in 2017. The Scottish government's aim is to equip "children and young people with the increasingly sophisticated and creative digital skills they need to thrive in modern society and the workplace" (Digital Scotland, 2017a, p. 24). It is evident that the Scottish government considers young people as important actors in the co-creation of the digital future.

Whilst the overall analysis of digital youth participation has become prevalent since the 2000s, the number of scholarly publications explicitly examining Scottish digital youth is limited. At the time of writing this article, there is no comprehensive review of the Scottish digital youth landscape. The brief analysis presented in this section is based on several academic publications (Coates, 2016; Miller, 2015; Mowbray, Hall, Raeside, \& Robertson, 2018) and industry reports (5 Rights Youth Commission, 2017; Wilson \& Grant, 2017).

Literature examining digital youth inclusion in Scotland includes analysis of examples of youth political participation and citizenship (Mclaverty et al., 2015), youth information behaviour and digital literacy (Coates, 2016; Miller, 2015; Mowbray et al., 2018), the impact of digital technologies on young people (Woods \& Scott, 2016), digital youth inclusion (Wilson \& Grant, 2017), digital literacy (Gangneux, 2019), and Scottish youth digital culture (Lyons, McCreanor, Goodwin, \& Barnes, 2017). For example, there is evidence of the positive impacts of youth digital participation in Scotland (Mclaverty et al., 2015; Mowbray et al., 2018). Studies of youth digital engagement during the Scottish Independence Referendum provided evidence of first-time voters using social media when searching and sharing political information (Mclaverty et al., 2015). There is also an indication that young Scots utilised social media while seeking employment (Mowbray et al., 2018).

In response to the increasing importance of digital technologies in young Scots' lives (Ofcom, 2018) many of Scotland's youth-centred organisations embedded digital communication solutions into their programmes. For example, LGBT Youth Scotland's digital chat counselling service allows young people to confidently reach a youth worker's support online (LGBT Youth Scotland, 2020). Young Scot, the national information and citizenship organisation supported by the Scottish government, uses a digital application to share information with their young people (Young Scot, 2019). Digital youth inclusion projects in Scotland offer, for example, digital literacy outreach programmes (Duncan, 2016), programming workshops for girls (Crawford, 2019), and access to digital tools (Citadel Youth, 2019).

The relationship between young people and digital technologies has also been explored by Scottish policymakers (European Commission, 2018), youth work practitioners (Youth Link Scotland, 2020), and young Scots themselves (5 Rights Youth Commision, 2017). In 2018, members of the Scottish Digital Youth Network (Youth Link Scotland, 2020) contributed to the publication of the European Commission (EC)'s Policy recommendations for developing digital youth work (European Commission, 2018). The EC's recommendations include (1) the 
development of a common understanding of digital youth work across Europe, (2) strategic development of European digital youth work practice, (3) consideration and incorporation of youth participation youth rights, and (4) application of evidence-based approaches to digital youth work (European Commission, 2018). The Scottish Digital Youth Network (Youth Link Scotland, 2020) is a network of practitioners who utilise digital technologies in their work with young people, which aims to "facilitate learning about new and innovative approaches in digital and developments within policy" (Youth Link Scotland, 2020).

In 2017, the 5 Rights Youth project was commissioned by the Scottish government to carry out a youth-led investigation and contextualisation of the UNCRC human rights treaty for digital technologies (5 Rights Youth Commission, 2017). The 5 Rights Commission was a group of 19 young people aged 14 to 21 from Scotland, whose work was commissioned by the Scottish government in the years 2016-2017. The role of the 5 Rights Commission was to advise the Scottish government on the importance of young people's digital rights and their implementation in youth digital inclusion programmes. Up to date, the 5 Rights Commission's youth-led report provides some of the most comprehensive overview of young people's digital participation in Scotland. Using a nationally representative survey of 1,675 young people, the 5 Rights Youth Commission also provided one of the most comprehensive overview of young Scots digital needs, aspirations, and barriers to digital participation.

Based on their findings, the 5 Rights Youth Commission proposed a set of recommendations for the policymakers. Recommendations for Scottish policy-making included utilising a rightsbased approach in terms of future digital policy interventions and young people's participation in the co-design of future policies. The 5 Rights Youth Commission also called for the UK government to emphasise the importance of 'young people's rights by design' to protect young people from exercise data collection and surveillance practices. The five rights proposed by the young people included: (1) right to remove; (2) right to know, (3) right to safety and support; (4) right to informed and conscious use; (5) right to digital literacy.

Literature also reveals other evidence of digital literacy shortages among young Scots (Coats, 2016; Wilson \& Grant, 2017). For example, a 2016 study suggests that disadvantaged youth from southern Scotland experienced "greater barriers to information access resulting from poor technology skills, information literacy, and social structures and norms” (Coats, 2016). Similar digital literacy issues were highlighted in a 2017 report, which suggested that in Glasgow, "one in ten unemployed young people (10\%) cannot send their CV online, while more than one in six (17\%) believe they would be in work today if they had better computer skills" (Wilson \& Grant 2017, p. 31). Issues relating to online safety, privacy, data control, and digital awareness have also been highlighted (5 Rights Commission, 2017). According to $52.1 \%$ of young people in Scotland, the greatest threats in the digital world include anonymity, bullying, and targeting, which encompasses "bullying online, trolling, grooming, and other targeted exploitations caused by anonymous contacts" (5 Rights Commission, 2017, p. 39).

The need for a nation-wide inclusive and accessible digital youth inclusion and digital citizenship education has also been examined in Scotland. For example, McGillivray et al. stressed the importance of a holistic and critical approach to digital youth engagement:

...critical digital citizenship agenda needs to be embedded in educational narratives [in Scotland], where young people are, through practice, asked to ponder how digitally mediated publics operate in the school setting and beyond. Integrating 'making' and 'thinking critically' about the benefits and dangers of pervasive digital 
media in and outside of school is imperative (McGillivray et al., 2016, p. 721).

Online accessibility and inclusion in digital youth participation have been defined as crucial elements of effective digital youth participatory interventions in Scotland. The review of Scotland's first National Youth Arts Strategy's digital programme revealed that "Scottish digital youth projects were challenged to think creatively when delivering in isolated or disadvantaged areas" (Hyder, 2016, p. 1). Online connectivity issues such as a lack of mobile phone signal or "patchy internet connection" have also been noted (Duncan, 2016; Wilson \& Grant, 2017; Harvey, 2016).

This brief review of the Scottish youth digital inclusion programmes and policy developments, reveals that young people require an ongoing support to meaningfully participate in the society in the digital era. The review reveals that many of the existing and corporate-led digital inclusion programmes provide young people in Scotland with opportunities to primarily develop their functional digital literacy skills. While these programmes provide educators with useful tools (e.g., iPads), they do not seem to provide recommendations on how to contextualise and critique their design and social impact. This lack of critical digital literacy in youth digital inclusion programmes might lead to the deepening of the big data divide.

\section{ADDRESSING THE DIGITAL AND BIG DATA INCLUSION: THREE AREAS FOR CONSIDERATION}

An analysis of literature produced by digital youth and digital inclusion researchers (including young researchers) reveals that three areas should be taken into consideration when planning the future of youth digital inclusion in Scotland. The analysis presented in this section provides a set of theoretical and practical considerations for youth digital inclusion project design and delivery. These considerations cover three areas of digital youth inclusion provision: (1) control and definition of the digital inclusion process; (2) holistic examination of young people's digital needs and aspirations, fears; and (3) consideration of young people's human rights in the digital age. These considerations provide a starting point for the discussion on digital youth inclusion practice in the context of the big data divide. They should not be viewed as guidelines to be strictly applied, but as prompts for a critical reflection among digital youth inclusion researchers, practitioners, and policymakers.

\section{DIGITAL YOUTH INCLUSION PROVISION: CONTROL AND DEFINITION OF THE PROCESS}

Young people need to develop digital literacy that will provide them with access to today's global job market. To address the digital literacy shortage, policymakers, educators, and companies emphasise the importance of digital inclusion programmes for young people (Loyds Bank, 2018). According to the UNESCO, digital literacy is considered a 'gate' skill required by employers (Chetty et al., 2017). In Scotland, policymakers argue that "ensuring the population is digitally literate and business needs for digital skills are met is key to driving economic competitiveness and capturing emerging opportunities" (Digital Scotland, 2017b, p. 4). However, the acceleration of digital progress and the associated digital literacy gap has also resulted in a policy-making paradox: 
(advanced) communications to avoid the serious disadvantages associated with limited connectivity. On the other hand, increased connectivity aggravates the inequality-increasing dynamics associated with the digital economy (Bauer, 2016, p. 28).

There is a notable amount of collaboration between governments and private digital companies to address the digital skills shortage among young people. For instance, in 2018, Facebook invested $£ 8.8$ million to train 10 million people in Europe by 2050 (Fioretti, 2018). Fioretti reports that Facebook's community hubs aim to offer digital literacy and online safety training to digitally excluded groups, including old people, young people, and refugees. In 2018, the First Minister of Scotland, Nicola Sturgeon, launched the Google Digital 'educational tour' around Scotland (FirstMinister.gov.scot, 2018). As indicated by Sturgeon, by providing digital literacy training to communities this [Google] bus will provide people with the digital literacy and confidence they 'need to reach their potential' (FirstMinister.gov.scot, 2018). In the context of formal education, in 2017, one Scottish school was selected to participate in Microsoft's Flagship School programme, whereby Microsoft's technology was utilised to develop students' digital literacies. As stated on the company's website, "The Microsoft Showcase Schools emphasise personalized learning for their students through the use of 1:1 and 1: many learning devices with current technology such as Windows devices, Azure, Office 365, OneNote, Minecraft: Education Edition, and more" (Microsoft, 2017). Another tech company, Apple, had a chance to enter a new market across Scotland by providing free iPads including in Edinburgh, the Scottish Borders and Perth, Kinross, and Glasgow. Despite the ethical dilemmas (e.g., corporate interest) associated with tech-corporations influencing the Scottish educational system, these collaborations are welcome by the Scottish education department (Kobie, 2018).

Although digital inclusion initiatives funded and managed by so called 'tech-giants' have proved to be useful for the Scottish education sector, it is crucial to examine the ethical implications of corporate-led digital inclusion interventions. For example, prior research indicates that corporate-supported digital inclusion programmes, "do not have a reputation of protecting or informing users who may be targeted by automatable, algorithmically driven processes that predict user behaviour" (Gangadharan, 2017, p. 598). In their review of corporate-supported digital inclusion initiatives, Gangadharan suggests that while these services provide digital literacy training and online access, they fail to provide learning on users' digital privacy and data collection. Gangadharan argues that corporate-sponsored digital inclusion projects choose to, "neglect topics of surveillance and the collection and monitoring of personal information for the purposes of social control" (2017, p. 598). Thus, it might be argued that many of the existing digital inclusion initiatives focus on the functional skills and not citizens' critical abilities to examine the socio-political aspects of their digital participation.

It is thus important to consider questions focusing on whose version and/or interpretation of digital inclusion is adopted in a youth setting. When organising a youth digital initiative in the era of the big data divide, it might be useful to consider the following questions: who defines and controls youth digital inclusion in our project? What are the rules and limitations of the approach taken? How can we ensure that our project does not contribute to the wider problem of the big data divide? How can these challenges be mitigated? If the existence of these power dynamics fails to be addressed, it is possible that through the implementation of the corporatedriven practice, young people become "embedded in information and communication infrastructures regardless of personal choice” (Gangadhara, 2017, p. 601). Thus, learning about internet access and its implications should be positioned within a commercial interest-free 
environment. Youth digital inclusion should aim not only to create opportunities to join the current digital infrastructures, but to equip young people with the critical skills needed to understand the power structures of the digital world. While the importance of digital literacy in employment should not be underestimated, it might be beneficial to frame digital inclusion within a wider context of digital citizenship, internet governance, and digital human rights.

\section{HOLISTIC EXAMINATION OF YOUNG PEOPLE'S DIGITAL NEEDS, ASPIRATIONS, AND FEARS}

Young people are often "simultaneously hailed as pioneers of the digital age and feared as its innocent victims" (2017, p. 658). In the literature, the spectrum descriptions of young people's roles in the digital world vary from co-creators and active agents of the digital change to vulnerable and apathetic users. The over reliance of these two opposing narratives in the context of youth digital inclusion services is critiqued by Helsper (2017). Helsper argues that existing digital youth inclusion studies tend to view digitally-excluded young people as those who are "left out" or under societal pressure to go online. Scholars (Helsper \& Reisdorf, 2016; Vartanova \& Gladkova, 2019) and digital youth workers in the United Kingdom (Wilson \& Grant, 2017) agree that the binary narratives of young people's relationship with digital technologies are no longer accurate or appropriate.

As indicated by Vartanova and Gladkova, given the multiple aspects of society's life, there is also more than one digital divide, therefore "the view of the digital divide as a binary distinction between information haves and have-nots is not appropriate" (2019, p. 195). Young people's motivations for digital participation (or lack of it) are complex, diverse, and most importantly not static. As Helsper and Reisdorf (2016) observe the reasons that cause people to disengage with the internet can be different, depending on national or cultural contexts, and they can also change over time. Moreover, an individual's ability to connect and navigate the digital world might be impacted by a variety of personal circumstances. For example, while some decide to choose to join a social media platform due to peer-pressure, others decide to take proactive steps towards digital exclusion by removing a digital presence altogether (Kale, 2018). As each young person's selection of the tools and dimensions for digital interaction is highly individual and contextualised, they should be provided with an array of opportunities to choose digital services that best fulfil their needs, which blend together ingredients from both online and offline sources (Granholm, 2016).

The need for a critical and in-depth examination of young people's digital needs is particularly important in the context of the big data divide. Academic debates examining the big data divide reveal insights into how misinformation, algorithmically driven discrimination, surveillance, privacy, and data profiling might impact young peoples' perceptions of the digital world. As argued by Kidron et al. (2018), "the tension between being governed by and devoted to their device is, in part, a result of the persuasive strategies baked into the digital services that children [and young people] use" (2018, p. 13). It is essential to frame young people's digital inclusion practices within the big data divide to acknowledge that, "crucial issues of the digital divide are not just technological - they are social, economic, cultural and political" (Selwyn, 2010, p. 357). Critical analysis of these different influences and contexts should be central to any youth digital inclusion intervention.

In Scotland, young people's digital literacy levels and learning needs have been examined by 
digital youth inclusion practitioners (Carnegie UK Trust, 2017; Wilson \& Grant, 2017) and policymakers (Youth Link Scotland, n.d). In 2019, Youth Link Scotland published a learning resource for youth digital inclusion workers. The resource provides information on how to frame digital inclusion not only as practical digital literacy but as a proactive and inquisitive mindset in digital times. As stated on the project's website, "adapting to the digital world is not just about emails, social media and online services, it's about maximising the opportunities and learning but also minimising the threats and misinformation that affect confidence, motivation and access for everyone" (Youth Link Scotland, n.d). The importance of a holistic approach towards young people's digital aspirations has also been outlined by the Scottish digital youth inclusion practitioners. For example, practitioners who took part in the youth digital inclusion initiative \#NotWithoutMe, emphasised that it is essential to test their assumptions about young people's digital literacy at the beginning of their projects (Carnegie UK Trust, 2017). Nonetheless, review of digital inclusion and youth digital inclusion in Scotland revealed that most projects' primary objective is in line with the Essential Digital Skills Strategy (Loyds Bank, 2019). It is worth noting that while the Essential Digital Skills Strategy provides useful guidelines for digital inclusion practitioners, it reinforces the dualistic view of those who are digitally included (employable and socially included) and those who are digitally excluded (unemployed, socially and economically disadvantaged).

It is argued here that any examination of such needs should be framed within the context of the big data divide as well as digital inclusion contexts. To better understand young people's attitudes towards digital technologies and address their digital needs, digital youth inclusion interventions analysis should aim to move away from an overly simplified, dualistic analysis of connected (or 'digital natives') vs. disconnected users, and passive vs. active users.

\title{
3. DIGITAL INCLUSION AND THE BIG DATA DIVIDE: YOUNG PEOPLE'S HUMAN RIGHTS
}

It is not enough for young citizens to be merely connected and present online. In the current data-driven society, young people must be able to develop skills to gather and analyse information, develop informed opinions, and share these perspectives with others (Mihailidis \& Thevenin, 2013). Critical engagement with digital society requires one's abilities to use, understand, and create media and communication in a variety of contexts (Ofcom, 2018, p. 1), such as political, cultural, and societal dimensions of data. As argued by Dencik:

\begin{abstract}
The processing of data from across our lives can fundamentally shape social relations, the kinds of information valued and what is 'knowable' and therefore acted upon. At the same time, data, and the way it is generated, collected, analysed and used, is a product of an amalgamation of different actors, interests and social forces that shape how and on what terms society is increasingly being datafied (Dencik, Redden, Hintz, \& Warne, 2019, p. 873).
\end{abstract}

The big data divide has an impact not only on citizens' self-awareness, but their entire web of interactions with society. As algorithmically driven, these are primarily managed and understood by those who have the appropriate finances, infrastructure, and expertise (Trappel, 2019; McCarthy, 2016; Zuboff, 2019). In the context of the big data divide, the consideration of human rights should be particularly important when working with disadvantaged young people. 
Youth social inclusion and participation are viewed globally as a right protected by the Convention of the Rights of the Child, which was established in 1959, and served as the basis for the Convention of the Rights of the Child (CRC) adopted by the United Nations in 1989 (UNICEF, 2010). Articles 12-15 are concerned with the specific rights of young people to participate, voice their opinions, freely assemble, and engage in discussions relating to their well-being (McMillan \& Simkiss, 2009). Human rights particularly related to youth digital inclusion include the right to privacy (Article 16), access to information from the media (Article 17), the right to freedom of expression (Article 13,), the right to freedom of association (Article 15), and protection from exploitation (Article 36) (see the Council of Europe's 2014 Guide to Human Rights for Internet Users for an overview of these articles). The importance of human rights in the digital age was outlined by the young people involved in the 5 Rights Youth Commission, who argued that: "The offline and online worlds are two equal and intertwined aspects of our lives. Our rights are still our rights whether we are on social media or out on the streets; we are still young people that need support and empowerment whether we are on our smartphone or in the classroom" (5 Rights Youth Commission2017, p.7).

Just like traditional forms of literacy, which are often understood within a rights-based approach, digital literacy and digital inclusion programmes should aim to provide young people with knowledge and skills for informed, conscious, and meaningful digital participation. Thus, learning within the digital inclusion should be viewed as "the social emancipatory process of understanding and expressing itself in the world" (Tygel \& Kirsch, 2016, p. 3). Critical reflection upon the role of human rights in the digital age should not be viewed as an additional element of the digital inclusion and employability programmes, but as a core element of the learning agenda as well as a human and civic right.

Young people's pro-active participation with the pre-agreed structures of the data society is essential to protecting civic rights and liberties and enabling active digital citizenship (Hintz et al., 2017). Digital youth inclusion initiatives literacy should aim to support youth's agency, the courage to question and resist autocratic data structures, and provide "a basic knowledge of the political economy of digital platforms" (Pangrazio \& Selwyn, 2019, p. 432). In the context of youth digital inclusion, young people should be viewed as pro-active and curious individuals, who have the ability to critique and question existing digital structures.

\section{CONCLUSION}

The aim of this article was to examine the emerging challenges associated with digital youth inclusion and the big data divide, and to suggest some critical considerations for digital youth inclusion practitioners. The analysis presented here was based on the scholarly discussion on digital youth participation (Eynon \& Geniets, 2016; Helsper, 2017; Livingstone \& Third, 2017), digital inclusion (Gangadharan, 2017; Livingstone \& Helsper, 2007; Scottish Government, 2017) and big data divide (Andrejevic, 2014; McCarthy, 2016). While the literature analysis was framed within a wider, international context, the discussion presented here is primarily situated within the Scottish one. Based on this analysis, I propose a set of theoretical and practical considerations for the design and delivery of digital youth inclusion projects. These considerations focus on three areas of digital youth inclusion provision: (1) control and definition of the process, (2) holistic examination of young people's digital needs and aspirations, fears, and (3) consideration of young people's human rights in the digital arena. These considerations provide a starting point for the discussions on digital youth inclusion practices in the context of the big data divide. 
To an extent, these considerations might also translate into practical implications for both youth digital inclusion practitioners and policymakers. For example, for digital inclusion initiatives to be meaningful to young people, it might be beneficial to directly involve them in their design process. In a practical youth digital inclusion workshop setting, questions such as 'what does it mean to be digitally included as a young person? ;'who decides if a young person is digitally included or not?'; 'who controls our digital inclusion process and what do we know about them?'- might be used to prompt critical discussion and provide a sense of ownership among young project participants. Similar youth-centred approaches might also be implemented in the context of policy-making. As evidenced by the Scottish government's (2017) collaboration with the young people from the 5 Rights Commission (2017), young people's involvement in digital policy design can provide important insights into their views on how to define, control, and manage youth digital inclusion. However, I argue that to holistically understand and address the continually evolving challenges associated with digital inclusion, policymakers should extend these efforts to collaborate with a wider range of young people of different abilities, cultural backgrounds, and of different socio-economic statuses. These policymakers efforts should also include a critical analysis of corporate-led youth digital inclusion programmes, their social impact (both individual and collective) and their potential influence on the big data divide.

To understand young people's digital literacy levels, questions about the aims and objectives of digital inclusion should be explored at the beginning of a project. Pre-existing frameworks (e.g., Essential Digital Skills) provide an important structure for digital inclusion project design and facilitation; however, these should be extended by a holistic analysis of young people's digital needs, aspirations, and fears. To achieve this, practitioners might consider trying using youthcentred, participatory methods for critical reflection. Examples of methods might include gaming, graffiti and comics-making (Digital Youth Work Project, 2020). Such methods might also help when exploring the socio-economic structures of the digital society, the big data divide, and their impact on youths' human rights. For resources and examples of good practice, digital youth inclusion practitioners might refer to the resources produced by the 5 Rights Framework (5 RightsYouth Commision, 2017), the European Digital Youth Work Network (Digital Youth Work Project, 2020), and 'My Data and Privacy Online. A toolkit for young people' (London School of Economics and Political Science, 2020).

However, it is important to note some of the challenges associated with the practical implementation of the youth digital inclusion recommendations proposed in this article. First, it is possible that their implementation might require extra time and resources. Many youth digital inclusion programmes take place within the Scottish youth community education sector, which has been severely underfunded in the last decade. In light of these funding cuts and an increasing need to provide evidence of impact to funders, many youth digital inclusion practitioners have no choice but to prioritise functional and easily quantifiable skills over critical thinking (Pawluczuk et al., 2019). To address this challenge, digital youth practitioners should be provided with appropriate and commercial interest-free support to reevaluate their practice, and when possible, try to implement some of my considerations into their practice.

While this article provides some considerations for future youth digital inclusion practice, it has also raised a number of issues and questions which require further research. First, there is limited knowledge as to if (and to what extent) youth digital inclusion exacerbates the problem of the big data divide. A review of youth digital inclusion strategies, their implementations, and evaluations could provide important information about project participants' learning experiences and their related outcomes. Valuable insights could also be gained by working alongside digital inclusion practitioners and/or young project participants. In this case, methods 
such as participatory methods, observation, and interviews could allow for an in-depth analysis of participants' perceptions of their digital inclusion.

Another problem is the lack of consensus of what it means for youth digital inclusion programmes to be effective, critical, and ethical. As many youth digital inclusion programmes are driven by tech-companies' terms and conditions, it is unclear who decides what it means to be a digitally included young person. Thus, questions related to the value and interpretation of youth digital inclusion impact should be explored in future research (Pawluczuk et al., 2019). To this end, researchers might consider examining both young people's and digital inclusion workers' perspectives. Finally, more research is needed to understand the feasibility of practical implementation of critical digital literacy (Polizzi, 2019) into youth digital inclusion projects. Have functional digital literacy skills been prioritised in youth digital inclusion projects? What are some of the challenges and opportunities associated with teaching critical digital literacy skills alongside functional digital literacy skills in a youth digital inclusion setting? These are some of the questions that can be explored in future research.

To conclude, although this article uses Scotland as a case study, the considerations presented here might be useful in other geographical and cultural contexts. I argue that for digital inclusion efforts to be truly empowering, young people's human rights should be central to any digital inclusion programmes. To this end, young people should not be viewed as passive receivers of digital literacy educational programmes, but as pro-active and critical digital citizens and rights-holders. Therefore, to work towards a more inclusive, ethical, and equal digital society, young people's voices should be central to digital inclusion research, practice, and policy intervention.

This article presents a number of limitations with regards to theory and its practical application. First, it is important to note that my analysis is based on a section of available literature and is not reflective of all youth digital inclusion policy-making efforts and programmes in Scotland. Second, the youth digital inclusion practice considerations presented here are situated within the Scottish context and thus might not be entirely applicable to different populations, as well as geographical and cultural contexts. 


\section{REFERENCES}

5Rights Youth Commission. (2017). Our Digital Rights: How Scotland can reaslie the rights of children and young people in the digital world.

http://respectme.org.uk/wp-content/uploads/2017/o6/Five_Rights_Report_2017_May-4.pdf

Akom, A., Shah, A., Nakai, A., \& Cruz, T. (2016). Youth Participatory Action Research (YPAR)

2.0: how technological innovation and digital organizing sparked a food revolution in East Oakland. International Journal of Qualitative Studies in Education, 29(10), 1287-1307. https://doi.org/10.1080/09518398.2016.1201609

Anderson, M., \& Jiang, J. (2018). Teens, social media \& technology 2018. Pew Research Center, 31, 2018.Andrejevic, M. (2014). The big data divide. International Journal of Communication, $8(1), 1673-1689$.

Bauer, J. M. (2016). Inequality in the information society [Working paper]. Quello Center, Michigan State University. https://doi.org/10.2139/ssrn.2813671

Carnegie UK Trust. (2017). \#NotWithoutMe Active Discussion Notes.

https://padlet.com/CUKT/notwithoutmeactivenotes

Citadel Youth. (2019). Citadel Youth Centre: Community based youth work in Leith since 1980. https://citadelyouthcentre.org.uk/

Council of Europe. (2014). Guide to Human Rights for Internet Users. Retrieved from: https://rm.coe.int/CoERMPublicCommonSearchServices/DisplayDCTMContent?documentId= o9000016804d5b31

Crawford, N. (2019). Girlguiding Paisley and YMCA join forces to get girls coding. Girlguiding Renfrewshire. Retrieved from: https://www.girlguidingrenfrewshire.org.uk/news/paisleynews/95-girlguiding-scotland-and-ymca-join-forces-to-get-girls-coding

de St Croix, T. (2018). Youth work, performativity and the new youth impact agenda: getting paid for numbers?. Journal of Education Policy, 33(3), 414-438.

https://doi.org/10.1080/02680939.2017.1372637

Dencik, L., Redden, J., Hintz, A., \& Warne, H. (2019). The ' golden view': data-driven governance in the scoring society, Internet Policy Review, 8(2), 1-24.

https://doi.org/10.14763/2019.2.1413

Digital Scotland. (2017a). Realising Scotland's full potential in a digital world: a digital strategy for Scotland. Scottish Government. https://www.gov.scot/publications/realisingscotlands-full-potential-digital-world-digital-strategy-scotland/

Digital Scotland. (2017b). Scotland's Digital Strategy: Evidence Discussion Paper. Scottish Government. https://www.gov.scot/publications/scotlands-digital-strategy-evidencediscussion-paper/

Digital Youth Work Project. (2020). Good Practice. Retrieved from:

https://www.digitalyouthwork.eu/good-practices/

European Commission. (2018). Developing digital youth work Policy recommendations, training needs and good practice examples. Publications Office of the European Union. 
https://doi.org/10.2766/782183

Eynon, R., \& Geniets, A. (2016). The digital skills paradox: how do digitally excluded youth develop skills to use the internet? Learning, Media and Technology, 41(3), 463-479.

https://doi.org/10.1080/17439884.2014.1002845

FirstMinister.gov.scot. (2018). Google Digital Garage launch [Press release].

https://firstminister.gov.scot/google-digital-garage-launch/

Fitton, D., Little, L., \& Bell, B. T. (2016). Introduction:HCI Reaches Adolescence. In D. Fitton, L. Little, B. T. Bell, \& N. Toth (Eds.), Human-Computer Interaction Series Perspectives on HCI Research with Teenagers (pp. 1-9). Springer. https://doi.org/10.1007/978-3-319-33450-9

Gangadharan, S. P. (2017). The downside of digital inclusion: Expectations and experiences of privacy and surveillance among marginal Internet users. New Media and Society, 19(4), 597-615. https://doi.org/10.1177/1461444815614053

Gangneux, J. (2019). Logged in or locked in? Young adults' negotiations of social media platforms and their features. Journal of Youth Studies, 22(8), 1053-1067.

https://doi.org/10.1080/13676261.2018.1562539

Granholm, C. P. (2016). Social work in digital transfer-blending services for the next generation [Doctoral dissertation]. University of Helsinki.

https://researchportal.helsinki.fi/en/publications/social-work-in-digital-transfer-blending-serv ices-for-the-next-ge

Harvey, C. (2016). Using ICT, digital and social media in youth work [Report]. National Youth Council of Ireland. https://www.youth.ie/wp-content/uploads/2019/o3/International-reportfinal.pdf

Helsper, E. J. (2017). A socio-digital ecology approach to understanding digital inequalities among young people. Journal of Children and Media, 11(2), 256-260.

https://doi.org/10.1080/17482798.2017.1306370

Hautea, S., Dasgupta, S., \& Hill, B. M. (2017, May). Youth perspectives on critical data literacies. Proceedings of the 2017 CHI Conference on Human Factors in Computing Systems, 919-930. https://doi.org/10.1145/3025453.3025823

Hyder, N. (2016). Evaluation of TTS.Digital [Report]. Research Scotland. https://www.creativescotland.com/resources/our-publications/plansand-strategy-documents/national-youth-arts-strategy/evaluationof-the-implementation-of-time-to-shine

Ito, M., Soep, E., Kligler-vilenchik, N., Shresthova, S., Gamber-Thompson, L., \& Zimmerman, A. (2015). Learning connected civics $\square$ : Narratives, practices , infrastructures. Curriculum Inquiry, 45(1), 10-29. https://doi.org/10.1080/03626784.2014.995063

ITU. (2019). ITU-D Digital Inclusion. https://www.itu.int/en/ITU-D/DigitalInclusion/Pages/default.aspx

Kobie, N. (2018, January 24). Cynical about Apple's move into UK schools? Well, it turns out they need all the help they can get. Wired. https://www.wired.co.uk/article/apple-everyone- 
can-code-teaching-schools-uk-ipad

LGBT Youth Scotland. (2020). Digital Support. https://www.lgbtyouth.org.uk/groups-andsupport/digital-support/

Livingstone, S., \& Helsper, E. (2007). Gradations in digital inclusion: Children, young people and the digital divide. New Media and Society, 9(4), 671-696.

https://doi.org/10.1177/1461444807080335

Livingstone, S., \& Third, A. (2017). Children and young people's rights in the digital age: An emerging agenda. New Media and Society, 19(5), 657-670.

https://doi.org/10.1177/1461444816686318

London School of Economics and Political Science. (2020). My Data and Privacy Online. A toolkit for young people. http://www.lse.ac.uk/my-privacy-uk

Loyds Bank. (2018). UK Consumer Digital Index 2018. Lloyds Bank

https://www.lloydsbank.com/assets/media/pdfs/banking_with_us/whats-happening/lb-consu mer-digital-index-2019-report.pdf

McCarthy, M. T. (2016). The big data divide and its consequences. Sociology Compass, 1O(12), 1131-1140. https://doi.org/10.1111/soc4.12436

McGillivray, D., McPherson, G., Jones, J., \& McCandlish, A. (2016). Young people, digital media making and critical digital citizenship. Leisure Studies, 35(6), 724-738.

https://doi.org/10.1080/02614367.2015.1062041

McMillan, A. S., \& Simkiss, D. (2009). The United Nations Convention on the Rights of the Child and HIV/AIDS. Journal of Tropical Pediatrics, 55(2), 71-72.

https://doi.org/10.1093/tropej/fmpo24

Mihailidis, P., \& Thevenin, B. (2013). Media Literacy as a Core Competency for Engaged Citizenship in Participatory Democracy. American Behavioral Scientist, 57(11), 1611-1622. https://doi.org/10.1177/0002764213489015

Ofcom. (2018). Adults' media use and attitudes report [Report].

https://www.ofcom.org.uk/_data/assets/pdf_file/o011/113222/Adults-Media-Use-and-Attitu des-Report-2018.pdf

Pangrazio, L., \& Selwyn, N. (2019). 'Personal data literacies': A critical literacies approach to enhancing understandings of personal digital data. New Media \& Society, 21(2), 419-437.

https://doi.org/10.1177/1461444818799523

Pawluczuk, A., Webster, G., Smith, C., \& Hall, H. (2019). The Social Impact of Digital Youth Work: What Are We Looking For?. Media and Communication, 7(2), 59-68.

https://doi.org/10.17645/mac.v7i2.1907

Polizzi, G. (2019). Information literacy in the digital age: why critical digital literacy matters for democracy. In: S. Goldstein (Ed.), Informed societies: why information literacy matters for citizenship, participation and democracy (pp. 1-23). Facet Publishing.

Porat, E., Blau, I., \& Barak, A. (2018). Measuring digital literacies: Junior high-school students' perceived competencies versus actual performance. Computers and Education, 126, 23-36. 
https://doi.org/10.1016/j.compedu.2018.06.030

Prensky, M. (2009). H. sapiens digital: From digital immigrants and digital natives to digital wisdom. Innovate: Journal of Online Education, 5(3).

https://nsuworks.nova.edu/innovate/vol5/iss3/1/

Selwyn, N. (2010). Schools and schooling in the digital age: A critical analysis. Routledge.

Scottish Government. (2017). Scottish household survey 2016: annual report [Report]. Scottish Household Survey Project Team, Scottish Government.

https://www.gov.scot/publications/scotlands-people-

annual-report-results-2016-scottish-household-survey/

Duncan, P. (2016). Mobile Children, Young People and Technology Project: An Exploratory

Study of Mobile Cultures' Use of Digital Technology and New Media for Living and Learning.

STEP: Centre for Mobile Cultures and Education.

Trappel, J. (2019). Inequality, (new) media and communications. In J.Trappel (Ed.), Digital Media Inequalities. Policies against divides, distrust and discrimination (pp.9-30). Nordicom.

van Deursen, A. J. A. M., \& Helsper, E. J. (2018). Collateral benefits of Internet use: Explaining the diverse outcomes of engaging with the Internet. New Media and Society, 20(7), 2333-2351.

https://doi.org/10.1177/1461444817715282

Vartanova, E., \& Gladkova, A. (2019). New forms of the digital divide. In J.Trappel (Ed.), Digital Inequalities. Policies against divides, distrust and discrimination (pp.193-213). Nordicom.

Weston, A., Lumley, T., \& Curvers, S. (2018). My best life: priorities for digital technology in the youth sector [Report]. NPC. https://www.thinknpc.org/resource-hub/my-best-lifepriorities-for-digital-technology-in-the-youth-sector/

Wilson, G., \& Grant, A. (2017). A digital world for all? Findings from a programme of digital inclusion for vulnerable young people across the UK [Report]. Carnegie UK Trust. Retrieved from https://d1ssuo7opg2vii.cloudfront.net/pex/carnegie_uk_trust/2017/10/NotWithoutMe2.pdf

Youth Link Scotland. (2020). Digital Youth Work Network.

https://www.youthlinkscotland.org/about-us/our-networks/digital-youth-network/

Youth Link Scotland. (n.d). Safe, Secure and Empowered.

https://www.youthlinkscotland.org/develop/developing-knowledge/digital-youth-work/safe-se cure-empowered

Young Scot. (2019). Young Scot (Version 2.3.5) [Mobile app]. Google Play Store.

https://play.google.com/store/apps/details?id=com.stormid.youngscot\&hl=en_GB

\section{FOOTNOTES}

1. The Office for National Statistics in the United Kingdom defines recent internet users as adults who have used the internet within the last three months

2. In 2018, Ofcom defined superfast Internet connections as those with speed of 30Mbit/s or higher and less than 30oMbit/s. 